\title{
Amelioration of Diabetes Mellitus Type II after Sleeve Gastrectomy_Data on Nationwide Survey on Quality Assurance in Bariatric Surgery in Germany ${ }^{*}$
}

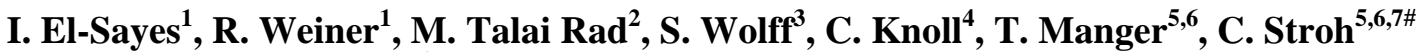 \\ ${ }^{1}$ Sachsenhausen Hospital, Frankfurt, Germany \\ ${ }^{2}$ Helios Hospital, Bad Saarow, Germany \\ ${ }^{3}$ Department of General, Abdominal and Vascular Surgery, University Hospital Magdeburg, Magdeburg, Germany \\ ${ }^{4}$ Stat Consult, Magdeburg, Germany \\ ${ }^{5}$ Department of General, Abdominal and Paediatric Surgery, SRH Hospital, Gera, Germany \\ ${ }^{6}$ Institute of Quality Assurance in Surgery gGmbH, University Magdeburg, Magdeburg, Germany \\ ${ }^{7}$ Competence Network Obesity, Germany

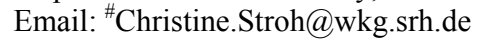

Received August 19, 2013; revised September 17, 2013; accepted September 25, 2013

Copyright (C) 2013 I. El-Sayes et al. This is an open access article distributed under the Creative Commons Attribution License, which permits unrestricted use, distribution, and reproduction in any medium, provided the original work is properly cited.

\begin{abstract}
Introduction: Sleeve Gastrectomy ( $\mathrm{SG}$ ) is becoming more popular due to its weight reducing effect and promising anti-diabetic efficacy. However, long term results are still lacking. Methods: The study focuses on anti-diabetic efficacy of SG through retrospective analysis of data for patients who underwent SG in Germany from 2005 to 2011. Anti-diabetic efficacy was assessed at 1, 2 and up to 4 years after surgery. Results: 5400 morbidly obese patients underwent SG. Of these 5400 patients $13.2 \%(n=712)$ were insulin treated (IT) and $21.6 \%(n=1165)$ were non-insulin treated (NIT). Total follow-up was accomplished in $41.24 \%$ of patients. Percentage of remission and improvement (RI) at 1 year was $83.8 \%(80.2 \%$ for insulin treated (IT) vs. $85.1 \%$ for non-insulin treated (NIT)). RI\% at 2 years dropped to $77.6 \%$ (76.9\% for IT vs. $77.9 \%$ for NIT patients). With late follow up (up to 4 years), RI\% was $65.9 \%$ (58.8\% for IT vs. $66.7 \%$ for NIT patients). Difference between IT and NIT patients was insignificant. Conclusion: SG shows promising ant-diabetic efficacy at 1 year, 2 years and up to 4 years after surgery. This efficacy gradually drops with prolonged time interval after surgery and seems to be insignificantly higher among NIT vs. IT patients.
\end{abstract}

Keywords: Sleeve Gastrectomy; Diabetes Mellitus Type II; Diabetes Remission; Metabolic Surgery

\section{Introduction}

Sleeve Gastrectomy (SG) was initially described as the first step of biliopancreatic diversion with duodenal switch in super obese patients [1]. Recently, stand-alone SG is gaining worldwide popularity, being a relatively non-technically demanding procedure with excellent results, in terms of substantial weight loss. Accordingly, SG is now approved as a definitive treatment in patients with a body mass index (BMI) $>40 \mathrm{~kg} / \mathrm{m}^{2}$ or BMI $>35$ $\mathrm{kg} / \mathrm{m}^{2}$ in diabetic patients [2-4]. This is due to the fact

\footnotetext{
"Conflict of interest: German Bariatric Surgery Registry is supported by BMBF with No. 01 GI1124.

The corresponding author confirms no links to these firms. The topic is presented in an independent light and the information outlined is product neutral.

${ }^{\#}$ Corresponding author.
}

that SG has an extended spectrum of action which covers additional satisfactory improvement of diabetic state [24]. It has also been proposed with encouraging results for diabetic non-morbidly obese patients with optimistic outcome [2-4]. Being a relatively recent technique, long term effect of SG is currently under research. This nationwide survey demonstrates long term anti-diabetic efficacy of SG in morbidly obese Germans who underwent SG from 2005 to 2011.

\section{Patients and Methods}

Patient selection: This data pool includes morbidly obese Germans who underwent SG between 2005 and 2011 in 107 hospitals cooperating with the German Bariatric Surgery Registry (GBSR), Institute of Quality Assurance in 
Surgery at the Otto-von-Guericke University of Magdeburg [5]. Data were collected in a prospective manner. That is to say, every year a new sample of population is added to the already existing cohort. After complete data collection, retrospective statistical analysis was done. Inclusion criteria conformed to the National Institutes of Health Consensus criteria [6]. The term (diabetes) refers to a clinical status with a fasting plasma glucose level of more than $126 \mathrm{mg} / \mathrm{dl}$ [7].

Assessment of diabetic profile was done at 1,2 and up to 4 years after SG. Accordingly, patients fell into one of four presentations, namely: remission, improvement, no change and deterioration. Remission, which can be either partial (improvement) or complete, was defined as achieving glycaemia below the diabetic range $(126 \mathrm{mg} / \mathrm{dl})$ in the absence of active pharmacologic (anti-hyperglycemic medications, immunosuppressive medications) or surgical (ongoing procedures such as repeated replacements of endoluminal devices) therapy [8].

\section{Statistical Analysis of Data}

Statistical analysis was performed by Stat Consult $\mathrm{GmbH}$ using SAS 9.2 software program. Descriptive statistical analysis was specified by presentation of absolute and relative frequencies for nominal values and mean, standard deviation, minimum and maximum values for continuous variables. Median was considered for high variation. Descriptive statistics were extended by frequency tests for several values and variables. For further verification of the differences between the variables $\chi^{2}$-test was used. Significant differences are shown if $\mathrm{p}<0.05$. Continuous variables of two groups were compared with two sample t-Test.

\section{Results}

The study included 5400 morbidly obese patients who underwent SG from 2005 through 2011. Their demographic data are demonstrated in Table 1. Of these 5400 patients who underwent SG $13.2 \%$ were insulin treated (IT) vs. $21.6 \%$ who were non-insulin treated (NIT). All these patients suffered on diabetes mellitus type II. Follow up was successfully accomplished in $34.7 \%$ patients after one year, $10.4 \%$ at two years and for $3.4 \%$ for patients up to 4 years. Those represent our cohort. This relatively low follow up rate is due to the fact that follow up program is not covered by the health insurance system in Germany.

Patients are divided in two major groups according to the anti-diabetic efficacy of SG: patients who show either remission or improvement of their diabetic status (RI) and those who show either no change of their diabetic status or deterioration (ND). Remission was defined of total loose of diabetes mellitus type II independent if the patient was treated with insulin or oral anti-diabetics. Several categories were defined patients could have a reduction of insulin dose at all, a reduction of the oral doses as well as a change from insulin to non-insulin treated diabetes type II. Also some patients developed diabetes in spite of weight reduction in case of better medical examinations. Table 2 illustrates all these changes as well as RI\% among patients (total, IT and NIT) after SG at 1, 2 and up to 4 years (Table 3). RI\% was higher, but statistically insignificant among NIT vs. IT patients at all follow up points.

Data on duration of diabetes prior to surgery were not available for these patients.

\section{Discussion}

Weight gain has always been referred to as a risk factor for impaired glucose tolerance. Moreover, anti-diabetic agents are usually associated with weight gain [9]. This twin association of diabetes and obesity was the corner stone for many studies centered upon simultaneous control of both metabolic disorders. Conservative methods proved to lack long-lasting efficacy [10]. Surgery seems therefore to be the most suitable alternative [10].

Among variable surgical options, SG has recently emerged as a possible remedy for both diabetes and obesity. Anti-diabetic effect of SG has even been proved to precede its weight reducing effect [11]. Being a relatively recent procedure, proper explanation of its mechanism of action is currently under research. It is suggested that $\mathrm{SG}$ is not simply an absolute restrictive maneuver. Fundus

Table 1. Demographic data of morbidly obese diabetics who underwent SG in Germany from 2005 through 2011 and incidence of associated co-morbidities.

\begin{tabular}{|c|c|c|}
\hline - & Gender: & \\
\hline & - Males & $1965(36.4 \%)$ \\
\hline & - Females & $3435(63.6 \%)$ \\
\hline- & Mean age in years: & 43.6 \\
\hline & - Males & 44.7 \\
\hline & - females & 42.9 \\
\hline- & Mean BMI in $\mathbf{~ g g} / \mathrm{m}^{2}$ : & 52.1 \\
\hline & - Males & 53.2 \\
\hline & - Females & 51.5 \\
\hline- & $\begin{array}{l}\text { Percentage of patients with } \\
\text { associated co-morbidities } \\
\text { (other than diabetes mellitus): }\end{array}$ & $89.7 \%$ \\
\hline & - Hypertension & $65.9 \%$ \\
\hline & - $\quad$ Skeletal diseases & $49.8 \%$ \\
\hline & - $\quad$ Sleep apnea & $26.9 \%$ \\
\hline
\end{tabular}


Table 2. Changes of diabetes mellitus type II at 1, 2 and up to 4 years after SG for IT, NIT patients and for the total cohort.

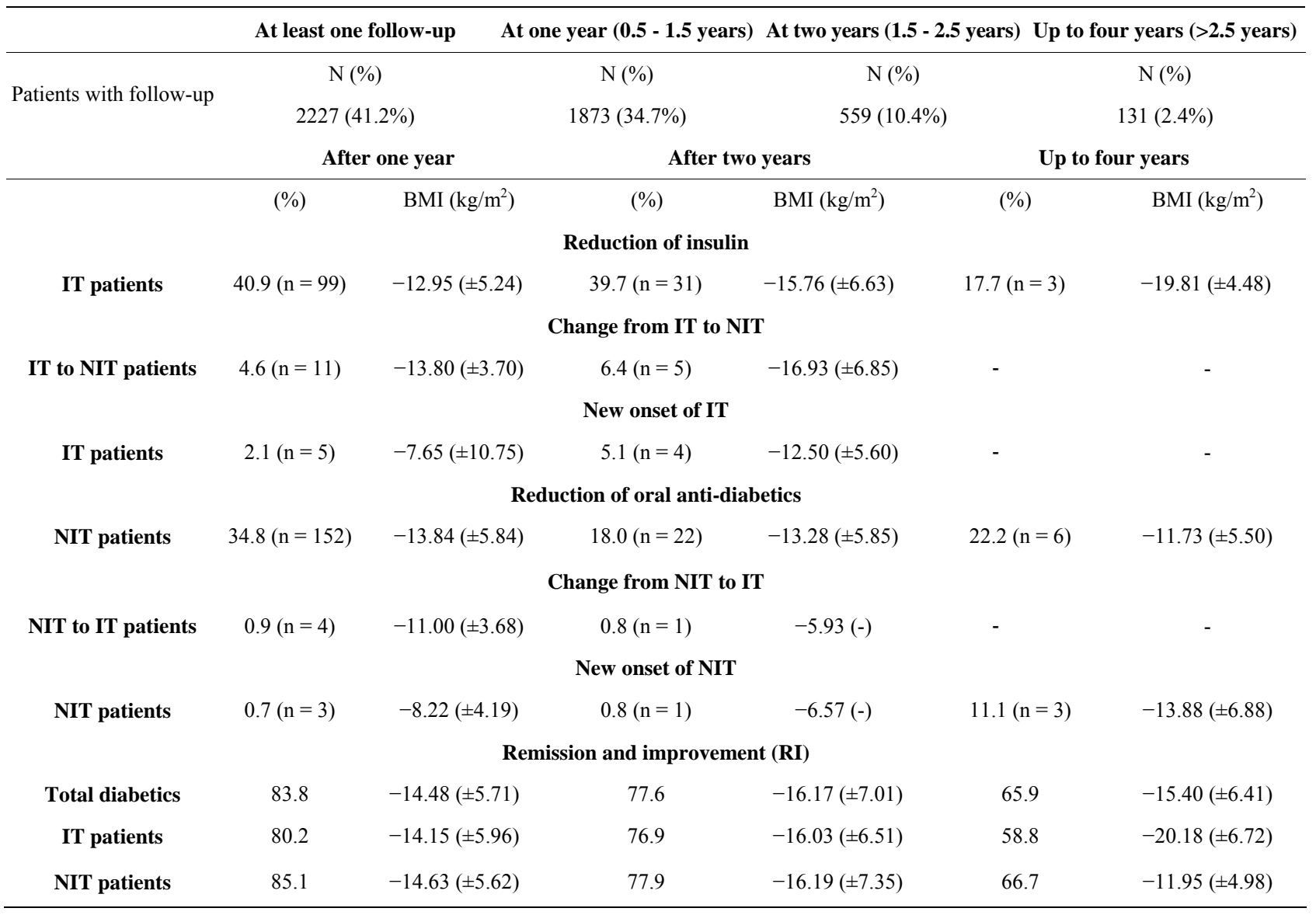

IT: insulin treated, NIT: non-insulin treated.

Table 3. Follow-up rate of patients at 1, 2 and up to 4 years after primary SG.

\begin{tabular}{ccccc}
\hline & At least one follow-up & At one year (0.75 - 1.25 years) At two years (1.75 - 2.25 years) & Up to four years (>2.25 years) \\
\hline Patients with follow-up & $\mathrm{N}(\%)$ & $\mathrm{N}(\%)$ & $\mathrm{N}(\%)$ & $\mathrm{N}(\%)$ \\
& $2227(41.2 \%)$ & $1837(34.7 \%)$ & $599(10.8 \%)$ & $131(2.4 \%)$ \\
\hline
\end{tabular}

IT: insulin treated, NIT: non-insulin treated.

resection, with resultant reduction of orixegenic ghrelin hormone, results primarily in post-operative weight loss. However, ghrelin hormone proved as well to have diabetogenic effect [12]. This together with rapid gastric emptying, shorter bowel transit time and post-operative rise of serum incretins (glucagon-like-peptide-1 and peptide-YY) seem to augment its anti-diabetic effect $[13,14]$. These findings could partly explain the anti-diabetic effect of SG.

Although this potential to control diabetes seems to be higher with RYGB if compared to SG $[15,16]$, SG seems however to have promisingresults. An efficacy of $88 \%$ was observed in less than one year after SG in diabetic patients [17]. This group of patients required only 6 months to achieve a mean HbA1C level of $6 \%$. Our re- sults go in accordance. Within one year after surgery, $83.8 \%$ of our patients had RI of their diabetic state.

Ruiz-Tovar et al. noticed that $83.3 \%$ of patients discontinued their hypoglycemic medications within one month after SG. These findings were maintained for 24 months after surgery [18]. In this survey, a more or less stationary RI\% was noticed at midterm follow up intervals of 2 years after SG, where RI\% dropped slightly to $79.5 \%$.

SG is the newest member among all obesity procedures. Long-term efficacy of SG is therefore currently lacking. However, some reports in literature studied the anti-diabetic efficacy of SG five years after surgery and attributed normalization of fasting blood sugar and $\mathrm{HbA} 1 \mathrm{C}$ encountered in $76.9 \%$ of their patients to $\mathrm{SG}$ 
[19]. We noticed that $65.9 \%$ of our patients maintained their diabetes free state with long-term follow up interval (up to 4 years). Abbatini et al. in analysis of long term effects of SG noticed an anti-diabetic efficacy, starting by $87.8 \%$ one year after surgery, gradually decreasing to $84.6 \%$ at two years and further dropped to $76.9 \%$ at five post-operative years. Similarly our cohort showed that $83.8 \%$ of patients achieved RI within 1 year after SG. This percentage dropped gradually to $77.6 \%$ at 2 years and $65.9 \%$ up to 4years after operation respectively.

Reports about anti-diabetic efficacy of SG highlighted a clinical situation of persisting diabetes after operation. This could be encountered in type 1 insulin treated diabetics with autoimmune destruction of pancreatic beta cells. It is therefore recommended to exclude this condition before surgery to optimize surgical outcome [20]. Schauer et al. similarly noticed an $87 \%$ reduction in the number of patients requiring oral anti-diabetic medications after surgery vs. only $79 \%$ reduction among the insulin requiring group [21]. In the same way, NIT patients in our cohort showed a higher RI\% than IT at all follow up intervals. This difference was statistically not significant.

Although this report demonstrates in our opinion long term outcome of a relatively recent surgical procedure, which is lacking in most published studies, our database lacks however accurate assessment of pre- and post-operative $\mathrm{HbA1C}$ levels. This is a limitation in this survey. Moreover, the follow up rate for our patients is relatively low. However, this is attributed to the fact that follow up of patients is not covered by health insurance service in Germany.

\section{Conclusion}

In conclusion, SG is rapidly expanding in Germany, due to its promising results in terms of post-operative weight loss. Its anti-diabetic efficacy, even in IT patients, seems also to play a role in its growing popularity. However, long term assessment of its anti-diabetic efficacy is currently under evaluation.

\section{Acknowledgements}

We thank the following firms for financially supporting the study: Johnson \& Johnson MEDICAL GmbH, Ethicon Endo-Surgery Deutschland, Norderstedt Covidien Deutschland GmbH, Neustadt/Donau Pharm-Allergan GmbH, Ettlingen.

\section{REFERENCES}

[1] G. Almogy, P. F. Crookes and G. J. Anthone, "Longitudinal Gastrectomy as a Treatment for the High-Risk Super-Obese Patient," Obesity Surgery, Vol. 14, No. 4, 2004, pp. $492-497$.

http://dx.doi.org/10.1381/096089204323013479

[2] M. Deitel, R. D. Crosby and M. Gagner, "The First International Consensus Summit for Sleeve Gastrectomy (SG), New York City, October 25-27, 2007," Obesity Surgery, Vol. 18, No. 5, 2008, pp. 487-496.

http://dx.doi.org/10.1007/s11695-008-9471-5

[3] M. Gagner, M. Deitel, T. L. Kalberer, et al., "The Second International Consensus Summit for Sleeve Gastrectomy, March 19-21, 2009," Surgery for Obesity and Related Diseases, Vol. 5, No. 4, 2009, pp. 476-485.

[4] M. Daskalakis and R. A. Weiner, "Sleeve Gastrectomy as a Single-Stage Bariatric Operation: Indications and Limitations," Obesity Facts, Vol. 2, No. S1, 2009, pp. 8-10. http://dx.doi.org/10.1159/000198239

[5] C. Stroh, R. Weiner, T. Horbach, K. Adipositas, A. Adipositaschirurgie, et al., "New Data on Quality Assurance in Bariatric Surgery in Germany," Zentralblatta fur Chirurgie, Vol. 138, No. 2, 2013, pp. 180-188.

[6] "NIH Conference Gastrointestinal Surgery for Severe Obesity. Consensus Development Conference Panel," Annals of Internal Medicine, Vol. 115, 1991, pp. 956-961.

[7] American Diabetes Association, "ADA Standards of Medical Care in Diabetes-2009," Diabetes Care, Vol. 32, No. S1, 2009, pp. S13-S61.

[8] J. B. Buse, S. Caprio, W. T. Cefalu, et al., "How Do We Define Cure of Diabetes?" Diabetes Care, Vol. 32, No. 11, 2009, pp. 2133-2135.

[9] F. X. Pi-Sunyer, "The Effects of Pharmacologic Agents for T2DM on Body Weight," Postgraduate Medicine, Vol. 120, 2008, pp. 5-17.

http://dx.doi.org/10.3810/pgm.2008.07.1785

[10] B. R. Smith, P. Schauer and N. T. Nguyen, "Surgical Approaches to the Treatment of Obesity: Bariatric Surgery," Endocrinology and Metabolism Clinics of North America, Vol. 37, No. 4, 2008, pp. 943-964. http://dx.doi.org/10.1016/j.ecl.2008.08.001

[11] J. S. Todkar, S. S. Shah, P. S. Shah and J. Gangwani, "Long-Term Effects of Laparoscopic Sleeve Gastrectomy in Morbidly Obese Subjects with Type 2 Diabetes Mellitus," Surgery for Obesity and Related Diseases, Vol. 6, No. 2, 2010, pp. 142-145. http://dx.doi.org/10.1016/j.soard.2009.06.008

[12] M. Dietel, M. Ganger, A. L. Erickson and R. D. Crosby, "Third International Summit: Current Status of Sleeve Gastrectomy," Surgery for Obesity and Related Diseases, Vol. 7, No. 6, 2012, pp. 749-759.

[13] I. Braghetto, C. Davanzo, O. Korn, et al., "Scintigraphic Evaluation of Gastric Emptying in Obese Patients Submitted to Sleeve Gastrectomy Compared to Normal Subjects," Obesity Surgery, Vol. 19, No. 11, 2009, pp. 15151521.

[14] F. Abbatini, D. Capoccia, G. Casella, F. Coccia, F. Leonetti and N. Basso, "Type 2 Diabetes in Obese Patients with Body Mass Index of 30-35 kg/m²: Sleeve Gastrectomy versus Medical Treatment," Surgery for Obesity and Related Diseases, Vol. 8, No. 1, 2012, pp. 20-24.

[15] J. Vidal, A. Ibarzabal, J. Nicolau, et al., "Short-Term Ef- 
fects of Sleeve Gastrectomy on Type 2 Diabetes Mellitus in Severely Obese Subjects," Obesity Surgery, Vol. 17, No. 8, 2007, pp. 1069-1074

[16] F. Rubino and M. Gagner, "Potential of Surgery for Curing Type 2 Diabetes Mellitus," Annals of Surgery, Vol. 236, No. 5, 2002, pp. 554-559. http://dx.doi.org/10.1097/00000658-200211000-00003

[17] M. Rizzello, F. Abbatini, G. Casella, et al., "Early Postoperative Insulin-Resistance Changes after Sleeve Gastrectomy," Obesity Surgery, Vol. 20, No. 1, 2010, pp. 5055. http://dx.doi.org/10.1007/s11695-009-0017-2

[18] J. Ruiz-Tovar, I. Oller, A. Tomas, et al., "Midterm Impact of Sleeve Gastrectomy, Calibrated with a 50-Fr Bougie, on Weight Loss, Glucose Homeostasis, Lipid Profiles, and Comorbidities in Morbidly Obese Patients," The American Surgeon, Vol. 78, No. 9, 2012, pp. 969-974.

[19] F. Abbatini, D. Capoccia, G. Casella, E. Soricelli, F. Leonetti and N. Basso, "Long-Term Remission of Type 2 Diabetes in Morbidly Obese Patients after Sleeve Gastrectomy," Surgery for Obesity and Related Diseases, Vol. 9, No. 4, 2013, pp. 498-502.

[20] M. Deitel, "Update: Why Diabetes Does Not Resolve in Some Patients after Bariatric Surgery," Obesity Surgery, Vol. 21, No. 6, 2011, pp. 794-796.

[21] P. R. Schauer, B. Burguera, S. Ikramuddin, et al., "Effect of Laparoscopic Roux-En y Gastric Bypass on Type 2 Diabetes Mellitus," Annals of Surgery, Vol. 238, No. 4, 2003, pp. 467-485. 